\title{
TWO-PHASE FRICTION FACTOR IN GAS-LIQUID PIPE FLOW
}

\author{
L. E. Ortiz-Vidal ${ }^{\mathrm{a}}$ \\ N. Mureithi ${ }^{\text {b, }}$ \\ and O. M. H. Rodriguez ${ }^{a}$ \\ ${ }^{\mathrm{a}}$ University of Sao Paulo (USP) \\ Sao Carlos School of Engineering \\ Department of Mechanical Engineering \\ Av. Trabalhador São-carlense 400 \\ CEP 13566-590, Sao Carlos - SP, Brazil \\ leortiz@sc.usp.br \\ LuisEnriqueOV@outlook.com \\ ${ }^{\text {b }}$ Polytechnique Montreal \\ Department of Mechanical Engineering \\ BWC/AECL/NSERC Chair of \\ Fluid-Structure Interaction \\ Département de Génie mécanique 2900 \\ H3T 1J7, Montreal - QC, Canada \\ Received: October 29, 2014 \\ Revised: November 30, 2014 \\ Accepted: December 30, 2014

\begin{abstract}
An improved friction factor prediction model for two-phase gas-liquid pipe flow is proposed. The model is based on a previous no-slip formulation where a mixture Reynolds number was defined. In this study, the mixture Reynolds number is modified by introducing slip-ratio information through experimental database reconstituted from the available literature and new frictional pressure-drop data for air-water horizontal flow in an I.D. $0.0204 \mathrm{~m}$ pipe are also presented. The full database considers several different flow conditions for horizontal two-phase flow of refrigerants and air-water mixtures. It was compared to predictions of models from the literature as well as the new proposed model. We found that the proposed and Müller-Steinhagen-and-Heck methods provide better agreement for the current experimental database. It is shown that the inclusion of void-fraction information on the previous mixture Reynolds definition improves the friction-factor prediction.
\end{abstract} \\ the inclusion of void-fraction and flow-pattern dependent models. An \\ Keywords: mixture Reynolds number, friction factor, two-phase flow, gas- \\ liquid flow, phenomenological modeling
}

\section{NOMENCLATURE}

A area, $\mathrm{m}^{2}$

$C_{1}, C_{2}$ proposed method constants

$d \quad$ diameter, $\mathrm{m}$

$d H \quad$ hydraulic diameter, $\mathrm{m}$

$d P / d L$ pressure drop gradient

e statistical parameter, $\%$

e/d relative roughness

$g$ gravitational constant, $\mathrm{m} / \mathrm{s}^{2}$

$J$ superficial velocity, $\mathrm{m} / \mathrm{s}$

$L_{\text {test }} \quad$ length of the test line, $\mathrm{m}$

$P \quad$ perimeter, $\mathrm{m}$

$P_{\text {system }}$ system pressure, $\mathrm{kPa}$

Re Reynolds number

$R e_{M} \quad$ Mixture Reynolds number by Shannak (2008)

$V \quad$ actual velocity, $\mathrm{m} / \mathrm{s}$

\section{Greek symbols}

$\alpha \quad$ void fraction

$\beta \quad$ homogeneous void fraction

$\xi \quad$ friction factor

$\eta \quad$ statistical parameter, $\%$

$\mu \quad$ viscosity, $\mathrm{Pa}-\mathrm{s}$

$\rho$ density, $\mathrm{kg} / \mathrm{m}^{3}$
Subscripts
exp experimental
$F \quad$ frictional
-FP flow pattern
$G \quad$ gas
$H \quad$ Homogeneous
I Interface
$L \quad$ Liquid
pred Predicted
$-\alpha \quad$ void fraction

\section{INTRODUCTION}

Pressure-drop prediction plays a relevant and important role in operation and design of pipeline systems. The Darcy method is the most popular for single-phase flow and its friction-factor estimation has been the focus of significant research efforts for over a century. It is known that for smooth pipes the friction factor is strongly related to the Reynolds number, but for pipes having significant roughness it also depends on the relative roughness (Colebrook and White, 1937). In the case of two-phase flow, some theoretical and experimental approaches have been developed to predict pressure drop. A review of the state-of-the-art can be found in 
Cravino et al. (2009). Many of the models are based on the no-slip homogeneous theory. According to García and García (2009), the models show good agreement with experimental data when an appropriate selection of the mixture viscosity and density equations is done. Following this approach, Shannak (2008) presents a no-slip model to predict the friction factor, and, consequently, two-phase frictional pressure drop. Shannak's formulation is original because it proposed a new concept by redefining the mixture Reynolds number. Recently, Ortiz-Vidal et al. (2012) showed that although the method by Shannak predicts the frictional pressure drop in horizontal air-water flow more accurately, when compared with classical methods (Chisholm, 1983, 1967; Dukler et al., 1964; Lockhart and Martinelli, 1949), the method excludes relevant two-phase flow information because of the homogeneous hypotheses.

In the present study, the mixture Reynolds number defined by Shannak is modified by introducing two-phase flow phenomenology through the inclusion of void-fraction and flow-pattern parameters. This approach avoids the need for adopting the no-slip homogeneous assumption of the original method. Therefore, an extension of the noslip model is proposed. The performance of the proposed model is evaluated through comparison with several reported models and new and available two-phase flow data from the literature.

\section{PROPOSED METHOD}

Shannak (2008) presents a methodology to estimate the friction factor for two-phase gas-liquid flow. The model is based on the redefinition of the mixture Reynolds number $\left(R e_{M}\right)$ as the ratio of the sum of inertial forces of the two phases over the sum of viscous forces of the phases,

$$
\operatorname{Re}_{M}=\frac{\sum F_{I}}{\sum F_{V}}=\frac{\rho_{L} J_{L}^{2} d^{2}+\rho_{G} J_{G}^{2} d^{2}}{\mu_{L} J_{L} d+\mu_{G} J_{G} d}
$$

No-slip considerations were adopted to evaluate $R e_{M}$. Shannak's model applies the homogeneous model (Wallis, 1969), using $R e_{M}$ in the friction-factor correlations obtained directly from single-phase-flow hydraulics, for example, correlation by Chen (1979),

$$
\begin{aligned}
& \xi_{\text {pred }}=\left[-2 \log \left(\frac{1}{3.7065}\left(\frac{e}{d}\right)\right.\right. \\
& \left.\left.-\frac{5.0452}{\operatorname{Re}} \log \left(\begin{array}{l}
\frac{1}{2.8257}\left(\frac{e}{d}\right)^{1.1098} \\
+\frac{5.8506}{(\operatorname{Re})^{0.8981}}
\end{array}\right)\right)\right]^{-2}
\end{aligned}
$$

where e/d represents the relative roughness. The proposed model is based on the approach of Shannak. However, further phenomenological information about the flow is included in the mixture Reynolds number. Inertial and viscous forces are evaluated as functions of the actual velocities and equivalent diameters of each phase,

$$
\operatorname{Re}_{M-\alpha}=\frac{\rho_{L} V_{L}^{2} d_{L}^{2}+\rho_{G} V_{G}^{2} d_{G}^{2}}{\mu_{L} V_{L} d_{L}+\mu_{G} V_{G} d_{G}}
$$

where $V_{L}\left(=J_{L} /(1-\alpha)\right)$ and $V_{G}\left(=J_{G} / \alpha\right)$ represent the actual velocity of liquid and gas, respectively. The separate-cylinder model is applied to determine the equivalent diameters (Wallis, 1969),

$$
\begin{aligned}
& d_{L}^{2}=(1-\alpha) d^{2} \\
& d_{G}^{2}=\alpha d^{2}
\end{aligned}
$$

In the particular case of separated flow, such as stratified and annular flow, equivalent diameters could be replaced by hydraulic diameters from geometrical considerations. Thus, the proposed method acquires a second version specifically for separated flow,

$$
\operatorname{Re}_{M-F P}=\frac{\rho_{L} V_{L}^{2} d_{H L}^{2}+\rho_{G} V_{G}^{2} d_{H G}^{2}}{\mu_{L} V_{L} d_{H L}+\mu_{G} V_{G} d_{H G}}
$$

where

$$
\begin{aligned}
& d_{H L}^{2}=C_{1}(1-\alpha) d^{2}, \quad C_{1}=(1-\alpha) C_{1^{*}}^{2} \\
& d_{H G}^{2}=C_{2} \alpha d^{2}, \quad C_{2}=\alpha C_{2^{*}}^{2}
\end{aligned}
$$

$C_{1 *}$ and $C_{2 *}$ are separated-flow parameters and are functions of the interfacial and phases perimeters (see Table 1). Table 2 presents the geometrical expressions for calculating the perimeters. In the case of stratified flow these perimeters were obtained considering a gas-liquid flat interface and are function of the dimensionless phase level $\left(h_{e}\right)$. For other flow patterns $C_{1}$ and $C_{2}$ are assumed to be equal to 1.0 according to the equivalent diameter approach. Flow pattern information is needed to evaluate $R e_{M-F P}$. The proposed models $R e_{M-\alpha}$ and $R e_{M-F P}$ include phenomenological information through the inclusion of void fraction and flow-pattern parameters.

Table 1. Parameters $C_{1 *}$ and $C_{2 *}$ of Eq. 5 .

\begin{tabular}{ccc} 
& $\boldsymbol{C}_{\boldsymbol{I}^{*}}$ & $\boldsymbol{C}_{2^{*}}$ \\
\hline If $V_{G}>V_{L}$ & $\boldsymbol{\pi} \boldsymbol{d} / \boldsymbol{P}_{\boldsymbol{L}}$ & $\boldsymbol{\pi d} /\left(\boldsymbol{P}_{G}+\boldsymbol{P}_{I}\right)$ \\
stratified/annular & & \\
else $\left(V_{G}<V_{L}\right)$ & $\boldsymbol{\pi d} /\left(\boldsymbol{P}_{\boldsymbol{L}}+\boldsymbol{P}_{I}\right)$ & $\boldsymbol{\pi d} / \boldsymbol{P}_{G}$ \\
stratified &
\end{tabular}


Table 2. Flow geometry for separated flow patterns stratified.

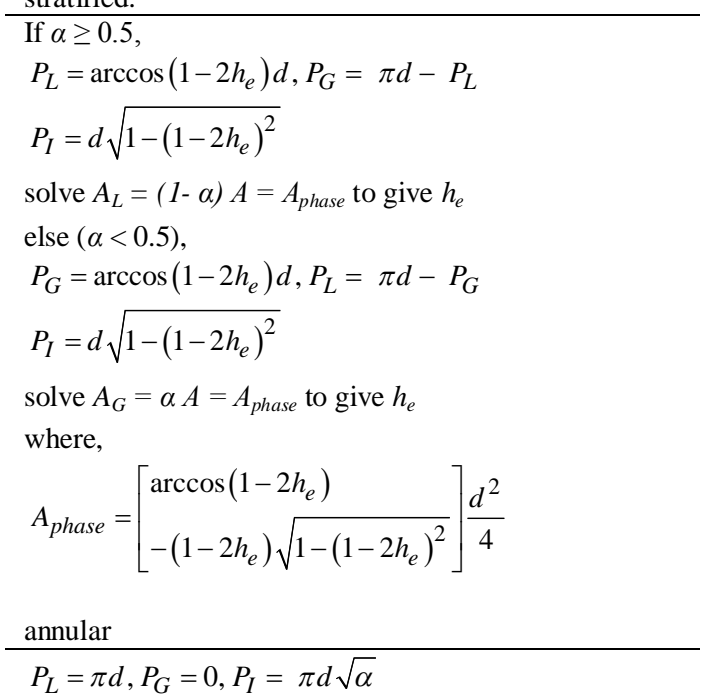

\section{EXPERIMENTAL WORK}

\section{Experimental facilities}

The experimental work was conducted at the Fluid-Structure Interaction Laboratory of the BWC/AECL/NSERC Industrial Research Chair, Polytechnique Montreal. Figure 1 illustrates schematically the two-phase test loop, where the main components and measurement instruments are designated by letters and numbers, respectively. The experimental setup was specifically constructed to study flow-induced vibration subject to two-phase pipe flow, according to Ortiz-Vidal (2012).

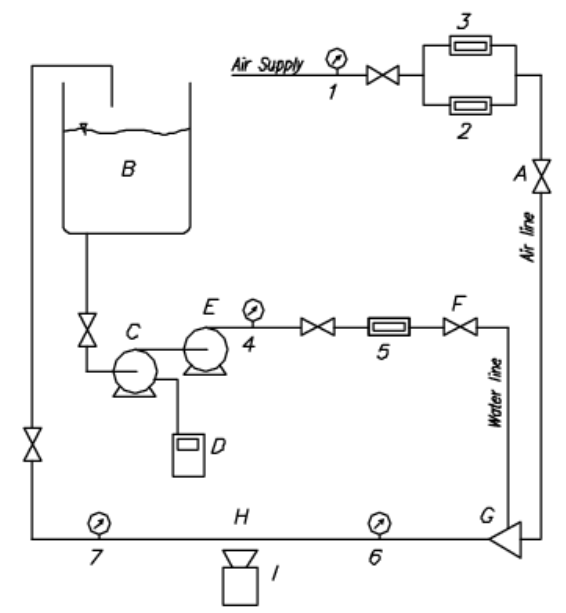

Figure 1. Schematic representation of the two-phase test loop. The letters and numbers represent the main components and measurement instruments, respectively.

Compressed air at steady pressure, controlled by the regulator 1 , is supplied into the system. The air flow rate is measured and regulated by the flowmeters 2 and 3 and the valve $A$. The air flowmeters $2(0-75 \mathrm{slpm})$ and $3(0-1000 \mathrm{slpm})$ have $1 \%$ and $1.5 \%$ FS accuracy, respectively. From an independent line, water at standard ambient temperature and pressure is pumped from the reservoir $\mathrm{B}$ by the centrifugal pumps $\mathrm{C}$ and $\mathrm{E}$. The liquid flow rate is set by a frequency inverter acting on the pump $\mathrm{C}$ and it is measured upstream by the flowmeter 5 with $0.25 \%$ RD accuracy. Air and water are mixed by means of a fitting type Y (G, Fig. 1). The two-phase mixture flows, in several flow patterns, through the test section (H, Fig. 1). The fluids are separated by gravity in the atmospheric tank B. The test section consists of a 3/4-in schedule 40 commercial clear PVC pipe with inner diameter $d=20.4 \mathrm{~mm}$ and a span of $L_{\text {test }}=90 \mathrm{~d}$.

In order to measure inlet and outlet pressure, pressure transducers $(0-50 \mathrm{psi})$ with $0.05 \% \mathrm{FS}$ accuracy (6 and 7, Fig. 1) are installed $L_{\text {test }}$ apart from each other. These collected signals were employed to calculate pressure drop and the effective pressure at the midspan position $\left(P_{\text {system }}\right)$. The latter was used to adjust the desired air flow rate. A hydrodynamic development length of $1760 \mathrm{~mm}(\approx 86 d)$, between the mixer exit and the first pressure tap (6, Fig. 1) was considered. This fact ensures a fully development flow for all tested conditions, according to the approach proposed by Ortiz-Vidal (2012). Images of the two-phase flow patterns were taken using the high-speed video camera system I located at the test section midspan position, i.e. $131 d$ away from the mixer exit. A program developed in LabVIEW $^{\mathrm{TM}}$ was used for acquiring and processing the signals. The sampling rate of $5000 \mathrm{~Hz}$ was chosen to ensure the accuracy of the sensors signals and to avoid the aliasing effect.

\section{Experimental conditions}

A set of 32 two-phase air-water flow conditions were investigated. The mixture velocity, $J\left(=J_{L}\right.$ $+J_{G}$ ), and the homogeneous (no-slip) void fraction, $\beta$ $\left(=J_{G} /\left(J_{L}+J_{G}\right)\right)$, were used to specify the experimental points. Every flow condition was set to the midspan position of the test section (H, Fig. 1). Hence the readings of the air flow meters were corrected by averaging the pressure values downstream and upstream (locations 7 and 6, Fig. 1). The nominal values of mixture velocities ranged from 0.5 to $25 \mathrm{~m} / \mathrm{s}$ and the homogeneous void fractions values were $\beta=10 \%, 25 \%, 50 \%, 75 \%$ and $95 \%$. Figure 2 shows the test conditions in terms of gas and liquid superficial velocities, $J_{G}$ and $J_{L}$, respectively.

Not only well-defined bubbly, dispersed and slug flow patterns, but also transition flow patterns were observed. For example, in the case of bubblydispersed flow transition, there are bubbles accompanied by small gas bubbles flowing on the top of the test sections; then, the presence of small 
bubbles increased and bubbles almost disappeared. Gradually the small bubbles occupied the pipe crosssectional area until it was completely filled, e.g. fully dispersed flow pattern. Similar bubbly-slug and slugdispersed flow pattern transitions were observed. In order to classify all tested conditions the flow pattern definitions of Shoham (2006) was used, taking into account the topological configurations predominantly observed. Figure 2 shows the results, where a good agreement between experiments and the flow map of Mandhane et al. (1974) is observed.

Table 3. Experimental results of the present study.

\begin{tabular}{ccccc}
$\begin{array}{c}J L \\
{[\mathrm{~m} / \mathrm{s}]}\end{array}$ & $\begin{array}{c}J G \\
{[\mathrm{~m} / \mathrm{s}]}\end{array}$ & $\begin{array}{c}P_{s y s t e m} \\
{[\mathrm{kPa}]}\end{array}$ & $\begin{array}{c}d P / d L_{F} \\
{[\mathrm{kPa} / \mathrm{m}]}\end{array}$ & $\begin{array}{c}\text { Pressure drop } \\
\text { uncertainty }( \pm)\end{array}$ \\
\hline 0.45 & 0.05 & 104.9 & 0.188 & $7.03 \%$ \\
0.91 & 0.10 & 107.1 & 0.714 & $4.37 \%$ \\
1.81 & 0.20 & 112.9 & 2.442 & $2.25 \%$ \\
2.70 & 0.29 & 123.5 & 5.033 & $1.18 \%$ \\
3.60 & 0.40 & 138.5 & 8.189 & $0.70 \%$ \\
4.51 & 0.50 & 157.4 & 12.095 & $0.46 \%$ \\
6.30 & 0.67 & 211.4 & 21.486 & $0.23 \%$ \\
0.38 & 0.12 & 105.0 & 0.188 & $6.94 \%$ \\
0.75 & 0.25 & 107.0 & 0.676 & $4.51 \%$ \\
1.50 & 0.49 & 113.4 & 2.329 & $2.13 \%$ \\
2.25 & 0.73 & 122.8 & 4.770 & $1.21 \%$ \\
3.00 & 0.99 & 137.2 & 7.888 & $0.72 \%$ \\
3.75 & 1.23 & 156.3 & 11.081 & $0.47 \%$ \\
5.25 & 1.73 & 214.2 & 17.993 & $0.22 \%$ \\
0.26 & 0.25 & 104.5 & 0.150 & $7.86 \%$ \\
0.50 & 0.50 & 105.6 & 0.376 & $5.85 \%$ \\
1.01 & 0.99 & 110.3 & 1.615 & $2.85 \%$ \\
1.49 & 1.50 & 117.6 & 3.268 & $1.58 \%$ \\
2.50 & 2.49 & 144.2 & 7.926 & $0.59 \%$ \\
3.50 & 3.55 & 181.9 & 12.997 & $0.31 \%$ \\
5.00 & 4.97 & 258.9 & 21.448 & $0.16 \%$ \\
0.24 & 0.75 & 104.3 & 0.263 & $8.39 \%$ \\
0.50 & 1.53 & 106.5 & 0.826 & $4.94 \%$ \\
1.25 & 3.80 & 121.2 & 4.207 & $1.30 \%$ \\
2.50 & 7.47 & 170.3 & 11.720 & $0.37 \%$ \\
3.75 & 11.07 & 276.1 & 24.153 & $0.14 \%$ \\
4.36 & 12.97 & 353.4 & 31.290 & $0.10 \%$ \\
0.24 & 4.75 & 104.5 & 0.826 & $8.47 \%$ \\
0.50 & 9.56 & 111.4 & 2.667 & $2.58 \%$ \\
0.75 & 14.27 & 125.3 & 5.597 & $1.09 \%$ \\
1.00 & 18.93 & 146.1 & 9.992 & $0.58 \%$ \\
\hline & 23.67 & 181.1 & 14.762 & $0.32 \%$ \\
\hline & & & & \\
\hline .25 & & \\
\hline
\end{tabular}

Table 3 shows the experimental superficial velocities, system pressure and frictional pressure gradient. The last column represents the combined uncertainty of the pressure transducers (6 and 7 ,
Figure 1). Relatively high uncertainty values are observed for low pressure-gradient values, as expected since the accuracy is calculated having as reference the pressure transducer's full scale.

\section{EXPERIMENTAL DATABASE}

Manageable two-phase-flow experimental data is quite scanty in the open literature. Most studies present experimental data in figures with swarms of points, which makes the identification of data points an impossible task. For this study, a reasonably broad pressure-drop database was collected from Kanizawa (2011), Moreno-Quibén (2005) and Shannak (2008). These literature data and the present experimental data are used to evaluate the proposed method. In total there are 412 experimental points considering several different diameters, working fluids and flow conditions. Table 4 shows the characteristics of the chosen database. DB, BB, IN, SL, SS, SW stand for dispersed bubbly, bubbly, intermittent, slug, stratified smooth and stratified wavy flow, respectively. In order to illustrate the full Table 4 database, the experimental flow map of Mandhane et al. (1974) was used, as shown in Fig. 2. It can be observed that the flow pattern of Mandhane et al. (1974) has a good agreement with Kanizawa (2011) and our own data. In the case of Moreno I and II databases, that author recommended the map by Wojtan (2004) to predict flow patterns Moreno-Quibén (2005). In this study, when comparing the flow map of Mandhane et al. (1974) and Wojtan (2004) an acceptable agreement was also found.

Experimental friction-factor data for two-phase flow was obtained from the pressure-drop database described in Table 4. The Darcy expression,

$$
\xi_{\exp }=\left(\frac{2 d}{\rho_{H} J^{2}}\right)\left(\left.\frac{d P}{d L}\right|_{F}\right)_{\exp }
$$

was used, where $\left(d P /\left.d L\right|_{F}\right)_{\text {exp }}$ is the experimental frictional pressure-drop gradient and $\rho_{H}\left(=(1-\beta) \rho_{L}+\right.$ $\left.\beta \rho_{G}\right)$ the mixture density assuming a no-slip homogeneous model (Wallis, 1969). The homogeneous mixture Reynolds number is used to correlate the Darcy friction factor. It is expressed by

$$
\operatorname{Re}_{H}=\frac{\rho_{H} J d}{\mu_{H}}
$$

where $\mu_{H}\left(=(1-\beta) \mu_{L}+\beta \mu_{G}\right)$ is the mixture viscosity (Dukler et al., 1964). The experimental friction factor, as a function of the homogeneous mixture Reynolds number, is presented in Fig. 3.

To calculate the experimental friction-factor, the temperature values reported by those authors of Table 4 were used. For the present data, a reference room temperature value of $20^{\circ} \mathrm{C}$, corresponding to the 
outlet fluid temperature of the test loop, was considered. We found that the air temperature has a very low influence on friction-factor calculation. A sensitivity analysis was carried out to evaluate the effect of temperature on mixture density. Simulations with air temperatures of $15^{\circ} \mathrm{C}$ and $25^{\circ} \mathrm{C}$ have shown that the deviation of friction factor values from those calculated at reference room temperature are negligible. The deviations calculated were up to $0.21 \%$. Figure 4 illustrates these results.

Table 4. Characteristics of database.

\begin{tabular}{l|ccccc} 
Source & Kanizawa (2011) & $\begin{array}{c}\text { Moreno I } \\
\text { Moreno-Quibén, } \\
2005)\end{array}$ & $\begin{array}{c}\text { Moreno II } \\
\text { Moreno-Quibén, } \\
\text { 2005) }\end{array}$ & Shannak (2008) \\
\hline Fluid considered & R134a & R22 & R134a* & Air-Water (AW) & Air-Water (AW) \\
Total data points & 134 & 96 & 71 & 79 & 32 \\
Diameter (mm) & 15.8 & 13.8 & 13.8 & 52.5 & not data \\
Flow Patterns (FP) & SW,SL,SS,IN & not reported & not reported & not reported & DB,SL,EB \\
Liquid superficial velocity $\left(J_{L}\right)$ & $0.003-0.19$ & $0.003-0.319$ & $0.005-0.23$ & $0.062-0.681$ & $0.245-6.303$ \\
Gas superficial velocity $\left(J_{G}\right)$ & $0.164-7.031$ & $1.259-21.66$ & $0.357-16.49$ & $0.477-34.56$ & $0.054-23.67$
\end{tabular}

* diabatic flow

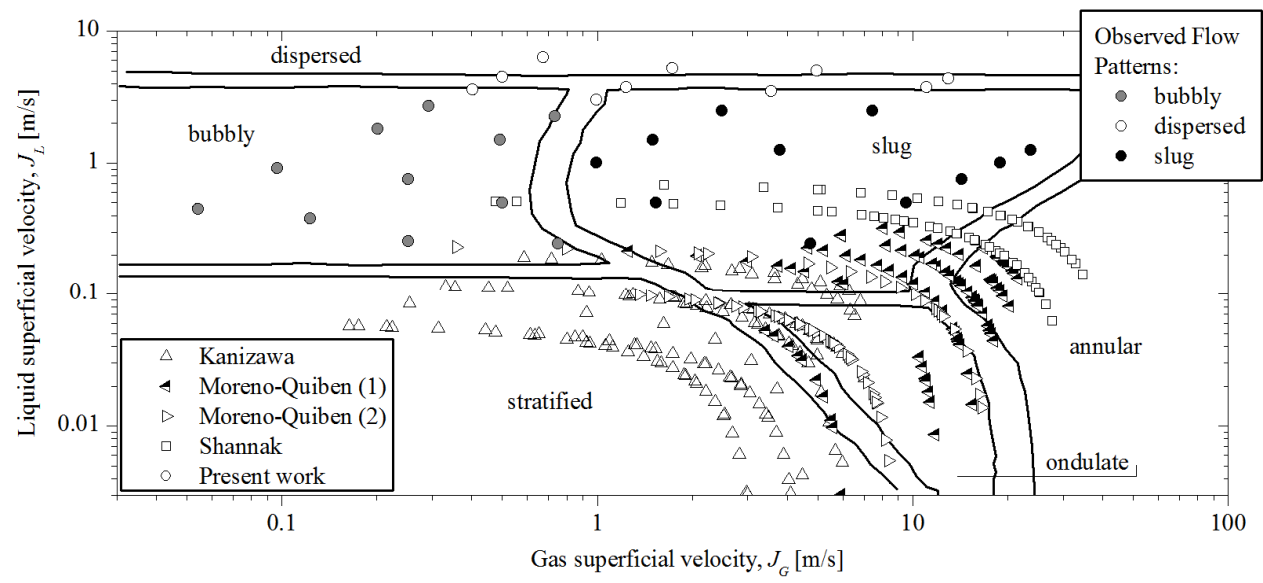

Figure 2. Table 4 experimental database on Mandhane et al. (1974)'s flow map. For the present work data, the grey, white and black circles $(\circ)$ represent the bubbly, dispersed and slug flow patterns, according to experimental observations, respectively.

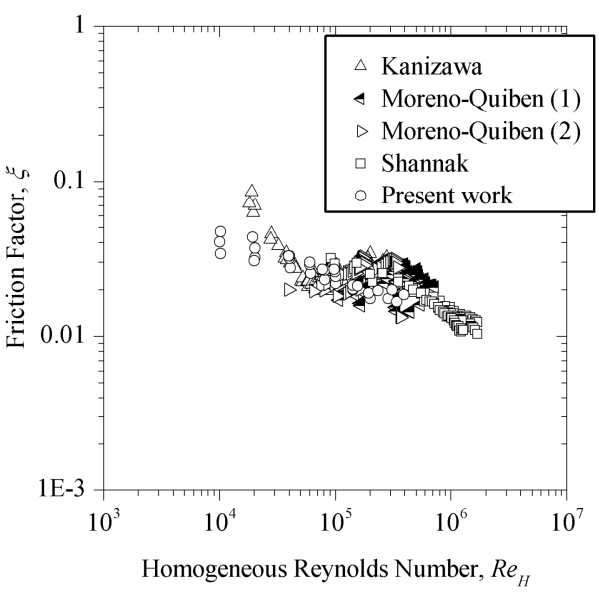

Figure 3. Friction-factor versus homogeneous Reynolds number, refer to Table 4.

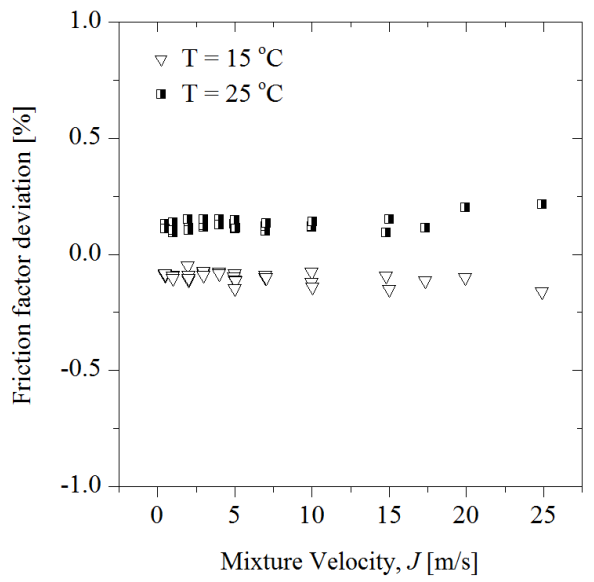

Figure 4. Friction-factor deviation versus mixture velocity. The deviations were calculated from a reference temperature-value of $20^{\circ} \mathrm{C}$. 


\section{METHOD EVALUATION}

The accuracy of the proposed method was tested with the experimental database shown in Fig. 3 and compared with the predictions of the following selected methods: Shannak (2008), no-slip homogeneous (Dukler et al., 1964), MüllerSteinhagen and Heck (1986) and García et al. (2007). The comparisons were at the same flow conditions compiled in Table 4. Two statistical parameters $e$ and $\eta$, representing the average absolute percent error and the percentage of data predicted within $\pm 30 \%$, respectively, were used.

$$
e=\frac{1}{n} \sum_{i=1}^{n}\left|\frac{\xi_{\text {pred }}-\xi_{\exp }}{\xi_{\exp }}\right| \times 100 \%
$$

The predictions of the proposed models, $R e_{M-\alpha}$ and $R e_{M-F P}$, were obtained using, respectively, Eq. (3) and Eq. (5) and the friction factor correlation of Chen (1979), Eq. (2). Notice that the proposed method is based on the inclusion of the void fraction as a parameter that contains two-phase flow information. Therefore, the correct estimation of void fraction is relevant. Two void-fraction correlations, Armand-Massina and Rouhani-Axelson, were tested (Woldesemayat and Ghajar, 2007). In the latter, a variation valid for flows of refrigerants was also used Wojtan (2004). In the specific case of the proposed $R e_{M-F P}$ method, flow pattern information was needed, Table 1. The flow maps of Wojtan (2004) and Mandhane et al. (1974) were used for Moreno I and II (Moreno-Quibén, 2005) and Shannak (2008) databases, respectively. Flow-pattern information for each experimental condition was available and thus employed in Kanizawa's and the present databases.

The models of Shannak and no-slip homogeneous were applied by substituting $R e$ by $R e_{M}$ (Eq. (1)) and $R e_{H}$ (Eq. (8)), respectively, in the friction-factor correlation of Chen, Eq. (2). The friction factor according to Müller-Steinhagen and Heck was obtained indirectly. First, the empirical method proposed by those authors was used to calculate the frictional pressure drop; then, the friction factor was obtained as described in the previous section, Eq. (7). The model of Garcia et al. (2007), referred as FFIUC in the original study, was performed using the parameters proposed by those authors. The parameters were obtained from the fitting of a comprehensive experimental database, mainly air-water flow conditions. To estimate the holdup they recommend the utilization of the holdup correlations of García et al. (2005). In this study, the so called theoretical correlation TMC was employed. At this point it is important to emphasize two things. First, Garcia et al.'s method originally provides predictions for the Fanning friction factor. We converted it to Darcy friction factor, ensuring consistency with the present study where the latter is used. Second, in the abovementioned holdup study other fitted correlations are also presented (García et al., 2005). However, when they are applied for the flow conditions presented in Fig. 2, a significant percentage of the holdup predictions were above one, which violates the law of conservation of mass. Therefore, those correlations were not used and only the correlation TMC was tested.

Table 5 shows the statistical evaluation of the selected prediction methods for the experimental database (Table 4). One can see a slight difference between friction factors predicted by the proposed method when using either the Armand-Massina or Rouhani-Axelson void-fraction correlations. These differences were less than $0.6 \%$ and $1.5 \%$ for the statistical parameters $e$ and $\eta$, respectively. It should be pointed out that both Armand-Massina and Rouhani-Axelson correlations are accurate (Woldesemayat and Ghajar, 2007). The agreement between the predictions of the proposed methods and the friction-factor database was fairly good (Table 5), except for Moreno II who ran their experiments under diabatic conditions. The poor predictions for diabatic flow of refrigerant suggest low accuracy in the estimations of the momentum (acceleration) pressuredrop component. This could be inferred from the void-fraction variation along the diabatic test section, according to Moreno-Quibén (2005). The proposed $R e_{M-F P}$ model provides the best prediction for Kanizawa (2011) and the present databases, with percent error $e=18.6 \%$ and percent prediction $\eta=$ $85.1 \%$ and $e=15.6 \%$ and $\eta=100 \%$, and the second best performance for Shannak (2008) and Moreno I databases, with $e=7.3 \%$ and $\eta=96.2 \%$ and $e=$ $24.0 \%$ and $\eta=70.8 \%$, respectively. In the diabatic flow case of Moreno II database, as cited above, a rather poor prediction was observed $(e=26.9 \%$ and $\eta$ $=54.9 \%)$. For this database, Müller-Steinhagen and Heck (1986) provides the best prediction with $e=$ $17.1 \%$ and $\eta=83.1 \%$. Moreover, the other selected methods had worse predictions than the proposed methods.

With respect to the present data, the proposed models $R e_{M-\alpha}$ and $R e_{M-F P}$ had the best predictions, as cited above. The values of $e=15.6 \%$ and $\eta=100 \%$ were the same for both, as expected since no separated flow was observed. The selected models also had a good agreement between experiments and predictions; sorted by accuracy they were García et al. (2007) ( $e=16.1 \%$ and $\eta=96.9 \%$ ), Shannak (2008) $(e=17.6 \%$ and $\eta=90.6 \%)$, Müller-Steinhagen and Heck (1986) $(e=19.3 \%$ and $\eta=84.4 \%)$ and no-slip homogeneous ( $e=21.5 \%$ and $\eta=81.3 \%$ ). Although García et al. (2007) had the second best performance for the present database, its predictions for the other databases were worse than the no-slip homogeneous method. The poor predictions for Kanizawa (2011), Moreno I and II (Moreno-Quibén, 2005) databases could be because García et al. (2007) correlation was not fitted for 
refrigerant two-phase flow. There is not an evident explanation of why García et al. (2007) also poorly predicts the air-water database of Shannak (2008). The range of experimental conditions of Shannak (2008) database are included on the database used by García et al. (2007) for fitting their own correlation. It might be simply a problem of extrapolation of García et al. (2007)'s results.

Table 5 also shows the statistical evaluation of the selected prediction methods classified by fluid and flow type. "Refrigerant" includes the diabatic and adiabatic flow conditions of refrigerants, i.e. Kanizawa (2011) and Moreno I and II databases. Kanizawa (2011) and Moreno I databases compose "Refrigerant Adiabatic". "AW" includes air-water flow conditions, i.e. Shannak (2008) and present databases. "Refrigerant Adiabatic \& AW" considers the databases for "Refrigerant Adiabatic" and "AW". Finally, "Total" represents the results for the full Table 4 database.

It can be observed that Müller-Steinhagen and Heck (1986) predicts reliably the two-phase friction factor for "Refrigerant". On the other hand, its predictions for "AW" are rather poor in comparison with the other methods. Müller-Steinhagen and Heck (1986) and both proposed-model versions had the best predictions for "Refrigerant Adiabatic", where diabatic flow is not consider. In the case of "AW", the proposed methods and Shannak (2008) predicted accurately these database. According to the previous description, and sorted by accuracy, proposed methods, Shannak (2008) and Müller-Steinhagen and Heck (1986) had better predictions for "Refrigerant Adiabatic \& AW". "Total" (last column of Table 5) presents Müller-Steinhagen and Heck(1986) and both proposed models as the most accurate ones. In general, García et al. (2007) has the worst predictions. It was also found that, on average, the proposed $R e_{M-F P}$ model, which considers flow-pattern information, does not offer significant improvements. Therefore, the proposed $R e_{M-\alpha}$ model has the advantage of being simpler to use.

Table 5. Statistical evaluation of the selected prediction methods for the experimental database (Table 4).

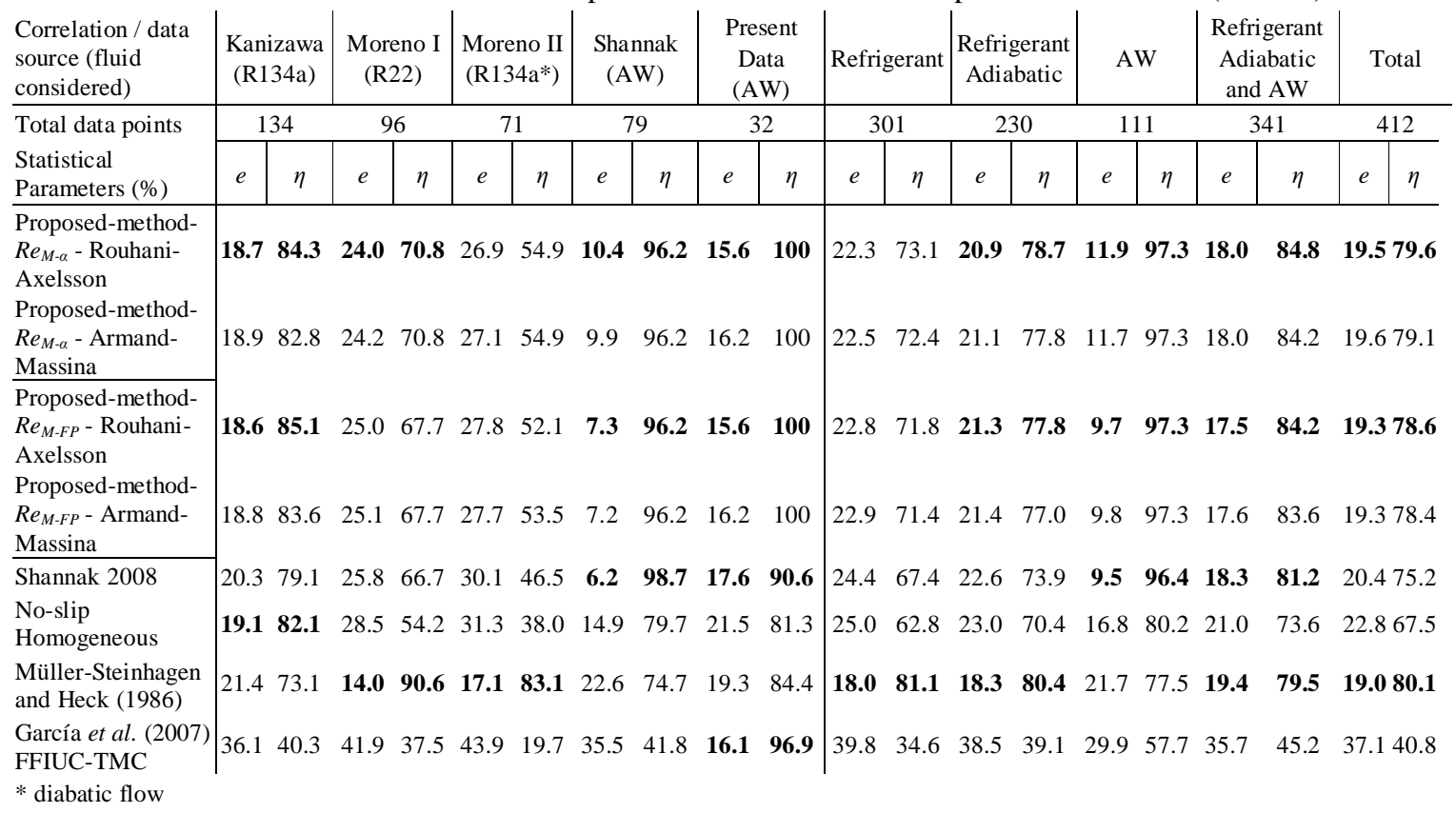

\section{CONCLUSIONS}

A method to predict the friction factor for twophase flow is presented. The model is based on the inclusion of void fraction in the mixture Reynolds number proposed by Shannak (2008). The voidfraction parameter introduces relevant two-phase flow information in the previous no-slip method. Two versions of the new model were proposed, depending on whether the flow pattern is known or unknown. Friction-factor predictions of the proposed model, Shannak (2008), no-slip homogeneous (Dukler et al., 1964), Müller-Steinhagen and
Heck (1986) and García et al. (2007) were compared with an available database of air-water and refrigerant diabatic and adiabatic two-phase flow from the open literature. Acceptable results are obtained with the proposed methods, Shannak (2008) and Müller-Steinhagen and Heck (1986). The latter provided the best prediction for refrigerant diabatic flow. On average, the proposed model where the flow pattern is known does not offer significant improvements. Therefore, the version of the proposed model where the flow pattern is unknown is recommended because it has the advantage of being simpler to use. García et al. (2007) and no-slip 
homogeneous methods had the worse accuracies. The results presented here indicate that the inclusion of void-fraction information in the mixture Reynolds number improves the predictions of friction factor.

\section{ACKNOWLEDGEMENTS}

The authors are grateful to Fabio Kanizawa, who kindly provided us with his collected data and to Gherhardt Ribatski and Marcelo de Souza Castro for their valuable comments. Luis Enrique Ortiz-Vidal gratefully acknowledges the support of the Petrobras/CNPq (proc. 151317/2014-3) and of BWC/AECL/NSERC Chair of Fluid-Structure Interaction, Polytechnique Montreal.

\section{REFERENCES}

Chen, N. H., 1979, An Explicit Equation for Friction Factor in Pipe, Industrial \& Engineering Chemistry Fundamentals, Vol. 18, pp. 296-297.

Chisholm, D., 1967, A Theoretical Basis for the Lockhart-Martinelli Correlation for Two-phase Flow, International Journal of Heat and Mass Transfer, Vol. 10, pp. 1767-1778.

Chisholm, D., 1983, Two-phase flow in pipelines and heat exchangers, Longman Inc., New York.

Colebrook, C. F., and White, C. M., 1937, Experiments with Fluid Friction in Roughened Pipes, The Royal Society, Vol. 161, pp. 367-381.

Cravino, A., Pérez, A. D., García, F., and García, J., 2009, Evaluación de Modelos Homogéneos, de Correlación y Mecanicistas en la Predicción del Gradiente de Presión de Flujo de Gas y de Líquido en Tuberías Verticales, Revista de la Facultad de Ingeniería, Vol. 24, pp. 75-82. (in Spanish)

Dukler, A. E., Wicks, M., and Cleveland, R. G., 1964, Frictional Pressure drop in Two-phase flow: B. An Approach Through Similarity Analysis, AIChE Journal., Vol. 10, pp. 44-51.

García, F., García, J. M., García, R., and Joseph, D. D., 2007, Friction Factor improved Correlations for Laminar and Turbulent Gas-liquid flow in Horizontal Pipelines, International Journal of Multiphase Flow, Vol. 33, pp. 1320-1336.

García, F., García, R., and Joseph, D. D., 2005, Composite Power law Holdup Correlations in Horizontal Pipes, International Journal of Multiphase Flow, Vol. 31, pp. 1276-1303.

García, J. M., and García, F., 2009, Efecto de la Viscosidad y de la Densidad de Mezcla en el Gradiente de Presión de Flujo Homogéneo GasLíquido en Tuberías Horizontales, Información Tecnológica, Vol. 20, pp. 95-106. (in Spanish)

Kanizawa, F. T., 2011, Theoretical and Experimental Study on flow Pattern Identification and Pressure drop During Single and Two-phase flow in Tubes with Twisted Tape Inserts, Master Thesis,
University of São Paulo, São Carlos, SP.

Lockhart, R. W., and Martinelli, R. C., 1949, Proposed Correlation of data for Isothermal Twophase, Two-Component Flow in Pipes, Chemical Engineering Progress, Vol. 45, pp. 39-48.

Mandhane, J. M., Gregory, G. A., and Aziz, K., 1974, A Flow Pattern Map for Gas-liquid Flow in Horizontal Pipes, International Journal of Multiphase Flow, Vol. 1, pp. 537-553.

Moreno-Quibén, J., 2005, Experimental and Analytical Study of Two-phase Pressure drops During Evaporation in Horizontal Tubes, Doctoral Thesis, Ecole Polytechnique Federale of Lausanne, Lausanne.

Müller-Steinhagen, H., and Heck, K., 1986, A Simple Friction Pressure Drop Correlation for Twophase Flow in Pipes, Chemical Engineering and Processing: Process Intensification, Vol. 20, pp. 297 308.

Ortiz-Vidal, L. E., 2012, Design of an Experimental Facility for Two-Phase Pipe Flow, Undergraduate Thesis, Pontifical Catholic University of Peru, PUCP.

Ortiz-Vidal, L. E., Mureithi, N. W., and Rodriguez, O. M. H., 2012, Pressure Drop in TwoPhase Gas-Liquid Horizontal Flow, in: VII Congreso Bolivariano de Ingenieria Mecánica, Cuzco, Peru.

Shannak, B. A., 2008, Frictional Pressure Drop of Gas Liquid Two-Phase Flow in Pipes, Nuclear Engineering and Design, Vol. 238, pp. 3277-3284.

Shoham, O., 2006, Mechanistic Modeling of Gas-Liquid Two-Phase Flow in Pipes, Society of Petroleum Engineers, Richardson, TX.

Wallis, G. B., 1969, One-dimensional Twophase Flow, McGraw-Hill.

Wojtan, L., 2004, Experimental and Analytical Investigation of Void Fraction and Heat Transfer during Evaporation in Horizontal Tubes, Doctoral Thesis, Ecole Polytechnique Federale of Lausanne, Lausanne.

Woldesemayat, M. A., and Ghajar, A. J., 2007, Comparison of Void Fraction Correlations for Different flow Patterns in Horizontal and Upward Inclined Pipes, International Journal of Multiphase Flow, Vol. 33, pp. 347-370. 